J. comp. Physiol. 90, 75-87 (1974)

(C) by Springer-Verlag 1974

\title{
Analysis of an Acoustic Pacemaker in Strecker's Chorus Frog, Pseudacris streckeri (Anura: Hylidae)
}

\author{
Jasper J. Loftus-Hills* \\ Section of Neurobiology and Behavior, Cornell University, \\ Ithaca, New York
}

Received December 6, 1973

Summary. In breeding assemblages of Pseudacris streckeri the mating call of one individual often occurs immediately after that of another. Calling by one male then becomes entrained to that of another even though their intrinsic call periods are different. The mechanism underlying entrainment was analysed by presenting acoustic stimuli to isolated males in the laboratory.

2 . When trains of acoustic stimuli at various rates were presented, males could entrain to stimuli with periods up to $60 \mathrm{msec}(18 \%)$ shorter and $50 \mathrm{msec}(15 \%)$ longer than their intrinsic call periods (Fig. 3). This range of periods corresponds to that found in natural populations (Table 1).

3. Each call-period consisted of three phases: (1) refractory phase-between beginning of period and up to $80 \mathrm{msec}$ before next call; (2) excitatory phasebetween end of refractory phase and beginning of call activation phase; (3) call activation phase-last 5-30 msec of call period. An acoustic stimulus presented during the excitatory phase normally evoked a call $30 \mathrm{msec}$ after the end of the stimulus, thus shortening the period by up to 50 msec. Stimuli occurring during the refractory or call activation phases did not evoke calls.

4. Since call periods can be lengthened by up to $50 \mathrm{msec}$, there must be a lengthened refractory or excitatory phase in the cycle following an acoustic stimulus; this is supported by the fact that the first free-run period following an evoked call is longer than the average call period (Fig. 6). Lengthening probably occurs in the excitatory phase.

5. The call activation phase probably represents neural transmission time between sound arriving at the ear and the resulting evoked call.

6. The acoustic system of $P$. strecker $i$ is discussed in terms of a central pacemaker with initiates each call and whose activity is modified in a predictable fashion by appropriate auditory input.

\section{Introduction}

In many species of animals, rapidly repeated, rhythmic, communicatory signals are emitted over long periods of time. The regularity with which these signals occur has led to the idea that a central neural pacemaker drives the motor system producing the signal. Acoustic signalling

\footnotetext{
* Present address: Museum of Zoology, The University of Michigan, Ann Arbor, Michigan 48104 , U.S.A.
} 
in insects (Jones, 1966; Shaw, 1968; Heiligenberg, 1969; Walker, 1969) and amphibians (Littlejohn and Martin, 1969; Lemon, 1971), and photic signalling in insects (Hanson et al., 1971) have been studied with this idea in mind. In all of these cases, properties of the hypothesized pacemaker were determined by modifying the normal signalling rhythm with appropriate sensory stimuli.

Individuals of many insect species alternate or synchronize signalling activity. However, interactions between frogs usually involve a sequential phenomenon where one individual signals immediately after another and then a relatively long interval occurs before the first animal signals again (see Loftus-Hills, 1971). This latter type of interaction has been described for a number of anuran species (Schmidt, 1964; Capranica, 1965; LoftusHills, 1971; Lemon, 1971) and occurs in Pseudacris streckeri, the subject of this paper. It has been suggested that the adaptive significance of this phenomenon may be that it minimizes the acoustic interference that would result from call-overlap (Loftus-Hills, 1971).

In the present study, a variety of acoustic stimuli were presented to males of $P$. strecker $i$ while they were emitting mating calls in a confined situation in the laboratory. The responses of these males to sounds resembling mating calls appeared similar to the acoustic interactions which have been observed in natural breeding assemblages. Attempts were made to determine the range of call rates in a natural population, the range of stimulus rates to which a male can be entrained ${ }^{1}$, and the mechanism of entrainment. It was hoped that such information would provide the framework for a model of the postulated pacemaker system in $P$. streckeri.

\section{Materials and Methods}

\section{Field Recording and Analysis of Mating Calls}

Mating calls of males of Pseudacris streckeri were recorded at a locality about $12.8 \mathrm{~km} \mathrm{NW}$ of Bastrop, Texas with a Uher 4000 Report $\mathrm{S}$ tape recorder and Uher M514 dynamic or Sony C-22 condenser microphone. All animals were calling from water. Water temperature was taken at each calling site. The recordings were analysed with a sound spectrograph (Kay 6061-A Sona-Graph) and storage oscilloscope.

\section{Experimental Studies}

Males of $P$. streckeri were collected from breeding assemblages $12.8 \mathrm{~km} \mathrm{N.W.}$ of Bastrop or about $5 \mathrm{~km} \mathrm{~W}$. of Austin, Texas. In order to maintain spontaneous calling in the laboratory it was found necessary to inject each animal intraperitoneally with human chorionic gonadotrophin (N.B. Co.) a few days before it was used in an experiment. Total dosage per animal varied from 200-1000 I.U.

Males were individually housed in small, cylindrical terraria each $12.7 \mathrm{~cm}$ in diameter and $17.8 \mathrm{~cm}$ high. A smaller container (diameter about $8 \mathrm{~cm}$ and height

1 Throughout this paper entrainment is used to describe a one to one association between stimulus and response. 
about $7 \mathrm{~cm}$ ) inside each terrarium was filled with water. The frogs usually called from the water.

Most experiments were performed when the frog had begun to call spontaneously. The terrarium, with frog inside, was placed in the center of an anechoic enclosure $(114 \times 69 \times 52 \mathrm{~cm})$ and about $40 \mathrm{~cm}$ from a loudspeaker (Nagra D.H. audioamplifier). Microphones (Uher M514 dynamic) were placed next to the terrarium and loudspeaker respectively and fed into a stereo tape recorder (Uher 4400 Report). Only one animal was tested at any one time.

Acoustic stimuli were formed by modulating the amplitude of a pure tone with a light-sensitive resistor and light-emitting diode driven in combination by an electrical stimulator (Grass S-5). Frequency, and rise and decay times of the resulting tone bursts were fixed at values similar to natural calls (see Results): $2125 \mathrm{~Hz}$ and $5 \mathrm{msec}$ respectively. These acoustic stimuli were then fed into the Nagra D.H. unit.

Stimulus intensity at the position of the frog was measured with a General Radio Co. Type 155-A sound level meter and was set at approximately $95 \mathrm{~dB}$ SPL (re 0.0002 dynes $/ \mathrm{cm}^{2}$ ). Field measurements of call intensity have not been made for this species but call intensities of the closely related form Pseudacris ornata (Gerhardt, 1973) and other hylids of comparable size (Loftus-Hills and Littlejohn, 1971) suggest that $95 \mathrm{~dB}$ SPL was a realistic value.

Ambient temperature during experiments was $22.5 \pm 1^{\circ} \mathrm{C}$.

The results were analysed with a PDP-8 digital computer (DEC Lab. 8/e) using programs for time interval histograms (DEC-LB-U42C-PB) and post stimulus time histograms (DEC-LB-U40B-PB). In some cases, stimuli and responses were fed into a two-channel pen recorder.

\section{Results \\ Field Recordings}

Calls of seven males were analysed and the principal call characteristics for each individual are shown in Table 1.

\section{Experimental Studies \\ Spontaneous Calling}

Time interval histograms were made of several minutes of calling for five individuals (Fig. 1). For individuals Nos. 3, 4, 5 and 6 no stimulus was presented during calling. For individual No. 2 , it was found necessary to induce calling with an acoustic stimulus; the stimulus was a continuous tone of $2125 \mathrm{~Hz}$ at about $95 \mathrm{~dB}$ SPL. Note that call periods ${ }^{2}$ are similar to those of field recorded calls (see Table 1), indicating that calling behavior in the laboratory and in the field is similar.

\section{Effects of Varying Stimulus Period ${ }^{2}$}

Each of five animals was presented with 22-25 series of stimuli, each series having a different stimulus period. Each series lasted for 30 sec with 30 sec intervals between series (individual No. 2, No. 3 and No. 4)

2 Call period and stimulus period are the reciprocals of call repetition rate and stimulus repetition rate respectively. 
Table 1. Mating call characteristics of seven males of Pseudacris streckeri

\begin{tabular}{lllllll}
\hline $\begin{array}{l}\text { Indi- } \\
\text { vidual }\end{array}$ & $\begin{array}{l}\text { Temperature } \\
\text { of water } \\
\left({ }^{\circ} \mathrm{C}\right)\end{array}$ & $\begin{array}{l}\text { Dominant } \\
\text { frequency } \\
(\mathrm{Hz})\end{array}$ & $\begin{array}{l}\text { Call } \\
\text { period } \\
(\mathrm{msec})\end{array}$ & $\begin{array}{l}\text { Duration } \\
(\mathrm{msec})\end{array}$ & $\begin{array}{l}\text { Rise } \\
\text { time } \\
(\mathrm{msec})\end{array}$ & $\begin{array}{l}\text { Fall } \\
\text { time } \\
(\mathrm{msec})\end{array}$ \\
\hline 1 & 19.7 & 2507 & 251 & 25 & 4 & 6 \\
2 & 19.7 & 2355 & 294 & 29 & 5 & 4 \\
3 & 19.7 & 2380 & 319 & 35 & 7 & 8 \\
4 & 19.0 & 2279 & 295 & 27 & 5 & 4 \\
5 & 20.0 & 2254 & 289 & 27 & 6 & 5 \\
6 & 19.5 & 2279 & 261 & 26 & 7 & 7 \\
7 & 19.5 & 2431 & 254 & 23 & 6 & 6 \\
Mean & 19.6 & 2355 & 280.4 & 27.4 & 5.7 & 5.7 \\
\hline
\end{tabular}

or 60 sec with 45-90 sec intervals between series (No. 5 and No.6). Stimulus periods varied from 70 to $600 \mathrm{msec}$. Stimulus duration was 25 msec. Order of presentation of series was random.

A time interval histogram of call periods during stimulus presentation was made for each series. For stimulus periods similar to the spontaneous call periods, histograms typically showed a single peak with stimulus and call periods the same (e.g. Fig. 2A). For shorter or longer stimulus periods, call periods were more variable (e.g., Fig. 2B). For each series the call period which occurred most often was determined from the time interval histogram and was plotted against stimulus period (Fig. 3). The occurrence of entrainment can be seen wherever the points fall on a slope of $45^{\circ}$ which begins at the origin. For all individuals, there were several stimulus periods for which there was entrainment. At much shorter and much longer stimulus periods, call periods were similar to those which occurred during spontaneous calling (see Fig. 3).

\section{Effects of Varying Stimulus Duration}

Six animals were presented with series of stimuli which varied in duration. In most cases the stimulus duration was changed without any pause in the presentation, but in some experiments intervals of $30 \mathrm{sec}$ or more occurred between series. Stimulus duration was varied from 10 to 200 msec. Post stimulus time histograms revealed one feature that was common to all individuals tested: in almost all histograms there were two distinct response-latencies ${ }^{3}$ separated by $27-46 \mathrm{msec}$ in individuals No. 1, No. 3, No. 4, No. 5, and No. 6 (Table 2 and Fig. 4 A, B) and 60 to 114 msec in individual No. 7 (Table 2 and Fig. 4C, D). The actual latencytime in relation to the stimulus duration varied between individuals. For

3 Response-latency corresponds to the time from the end of a stimulus to the beginning of the next call. 


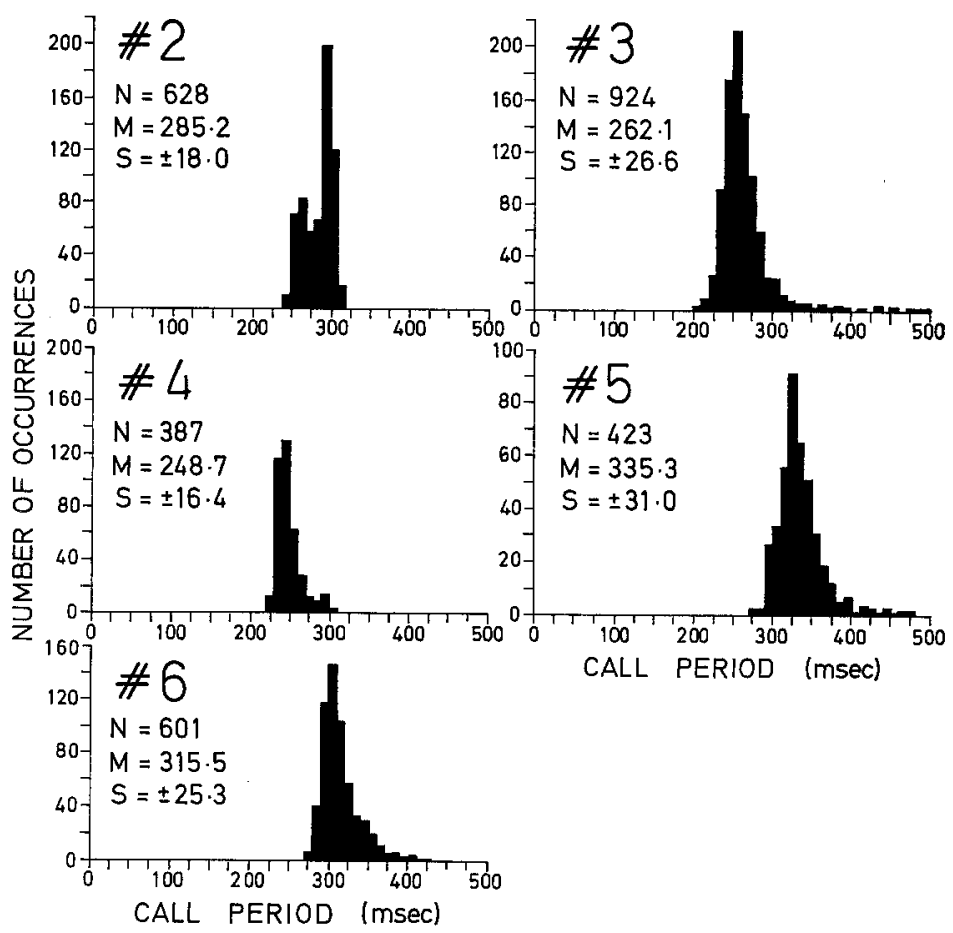

Fig. 1. Time interval histograms showing call periods of five individuals of $P$. streckeri. Each histogram represents several minutes of calling. Individuals Nos. 3, 4,5 and 6 were calling spontaneously. Individual No. 2 was stimulated to call with a continuous tone of $2125 \mathrm{~Hz}$ at about $95 \mathrm{~dB}$ SPL. Bin width: 10 msec. $N$ total number of occurrences; $M$ mean; $S$ one standard deviation from the mean
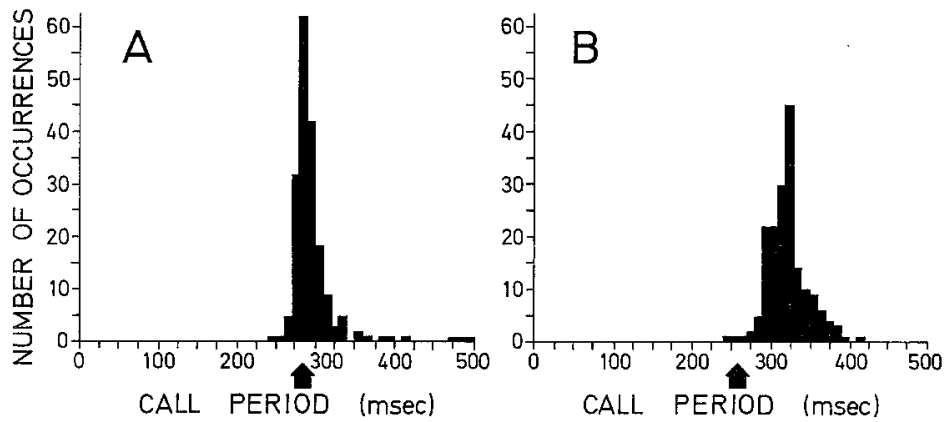

Fig. $2 \mathrm{~A}$ and $\mathrm{B}$. Time interval histogram showing call periods from two experimental series in which acoustic stimuli were presented to one individual every $285 \mathrm{msec}$ in one case (A) and every $256 \mathrm{msec}$ in the other (B). Bin width: $10 \mathrm{msec}$. Arrows indicate stimulus periods. Note that this individual (No.5) was entrained in one case (A) but not in the other (B) 


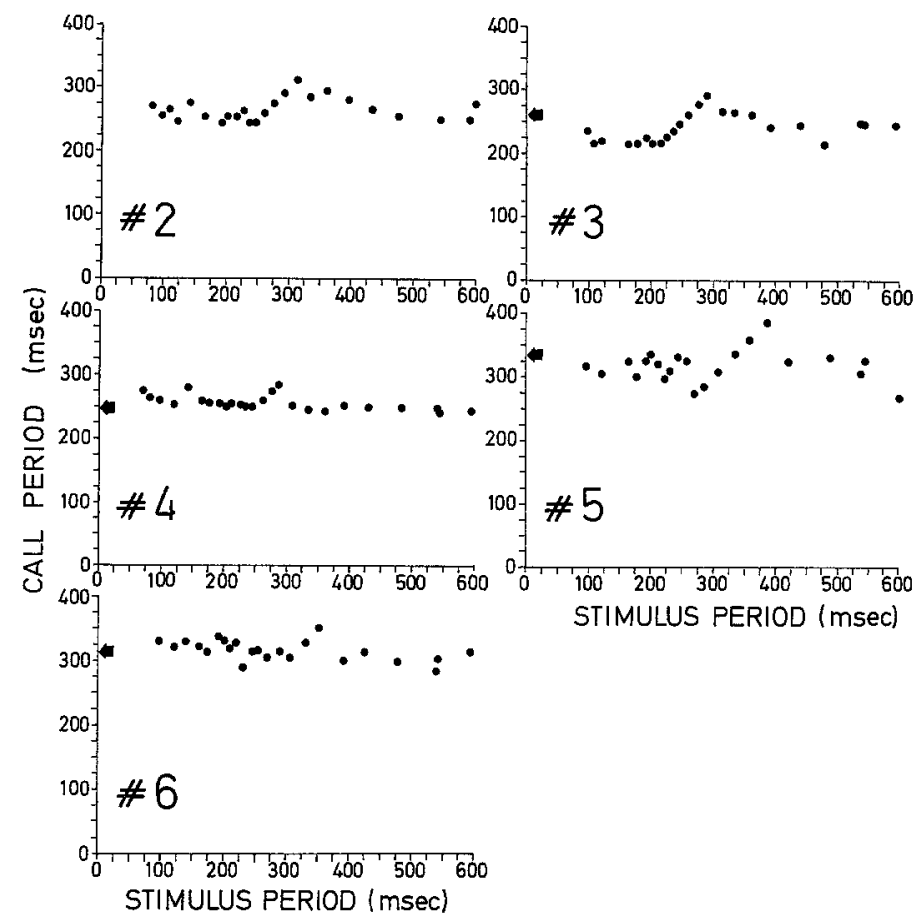

Fig. 3. Call period plotted against stimulus period for five individuals. Each value was obtained from a time interval histogram (for example see Fig. 2) representing 30 or 60 sec of stimulus presentation. Wherever entrainment occurred, values fall on a $45^{\circ}$ line beginning at the origin. Arrows indicate mean spontaneous call periods taken from Fig. 1. No arrow is shown for No. 2 because the spontaneous call period was not determined for this individual

Table 2. Time from beginning of stimulus to beginning of response for stimuli of different durations. Each value is taken from a post stimulus time histogram similar to those shown in Fig. 4. Wherever two latencies occured, two values are given. Each number in parentheses is the time from the end of the stimulus to the first response-latency. N.C. indicates that latencies were inconsistent and hence, no typical value could be determined. Values are in msec

\begin{tabular}{|c|c|c|c|c|c|}
\hline \multirow{2}{*}{$\begin{array}{l}\text { Indi- } \\
\text { vidual }\end{array}$} & \multicolumn{5}{|c|}{ Stimulus duration (msec) } \\
\hline & 10 & 25 & 50 & 100 & 200 \\
\hline 1 & $43(33)$ & $51(26)$ & $100(50)$ & N.C. & - \\
\hline 3 & $43,70(33)$ & $52,82(27)$ & $45,75(-5)$ & $126(26)$ & N.C. \\
\hline 4 & - & $52,82(27)$ & $81(31)$ & $131,170(31)$ & $226(26)$ \\
\hline 5 & - & $93(68)$ & - & $130^{\mathrm{a}}, 173^{\mathrm{a}}(20)$ & $200(0)$ \\
\hline 6 & $44,90(34)$ & $56(31)$ & $85,117(35)$ & $137,173(37)$ & 一 \\
\hline 7 & $50,110(40)$ & $53^{b}, 117^{b}(33)$ & $51,115(1)$ & $50,140(0)$ & - \\
\hline
\end{tabular}

a Stimulus was $110 \mathrm{msec}$.

b Stimulus was 20 msec. 


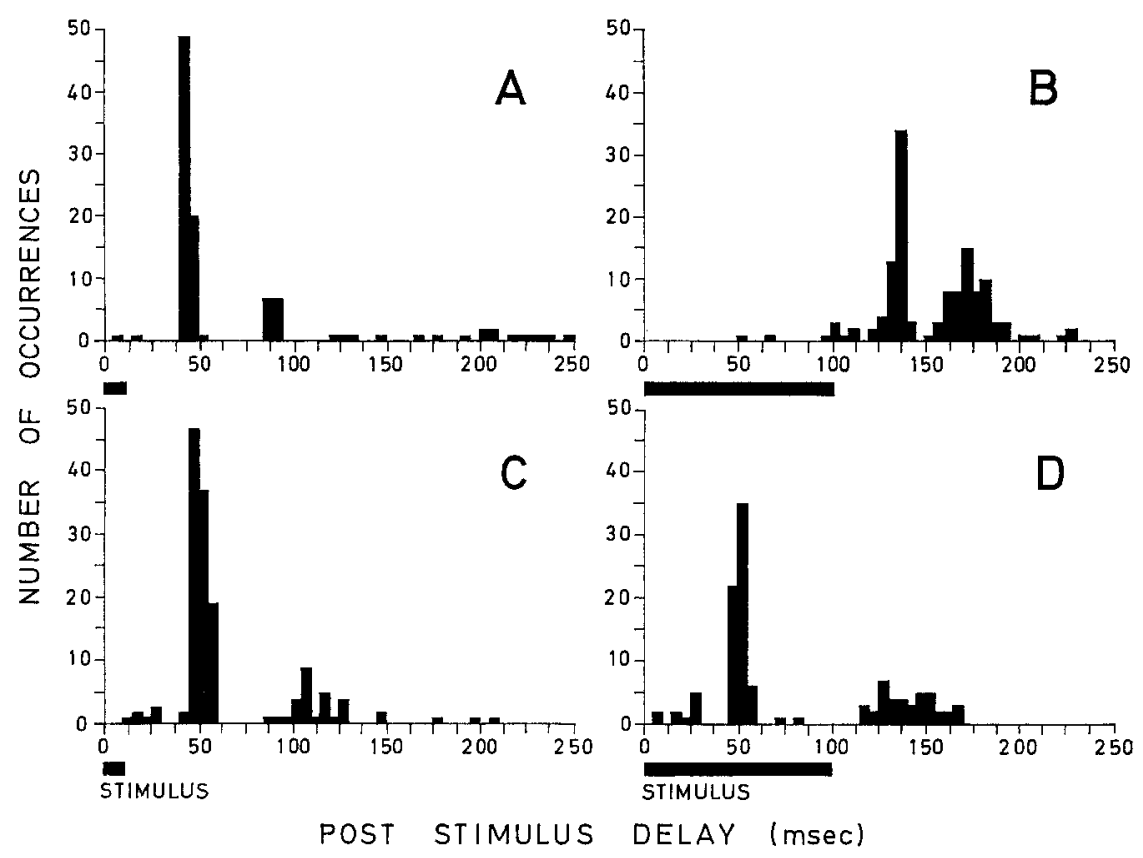

Fig. 4A-D. Post stimulus histograms showing time from beginning of stimulus to beginning of response for two individuals presented with stimuli at different durations: $10 \mathrm{msec}$ in A, C; $100 \mathrm{msec}$ in B, D. A, B, Individual No. 6. C, D, Individual No. 7. Stimulus period was $310 \mathrm{msec}$ for No. 6 and $440 \mathrm{msec}$ for No. 7. Bin width: $5 \mathrm{msec}$

individuals No. 1, No. 3, No. 4 and No. 6, the first response most often occurred 26-37 msec after the end of the stimulus. Thus, the end of the stimulus must normally be responsible for triggering the response. For No. 5, latencies were variable. For No. 7 , the first response always occurred about $50 \mathrm{msec}$ after the beginning of the stimulus even though the response overlapped with the stimulus at durations of 50 and $100 \mathrm{msec}$ (Table 2 and Fig. 4). No particular pattern was discernable in the relative occurrence of the shorter or longer response-latencies nor did both these response-latencies ever result from a single stimulus.

\section{Response-Latency}

Post stimulus time histograms made from stimulus series where entrainment occurred showed the expected concentration of shorter and longer response-latencies. However, series in which there appeared to be no entrainment still showed concentrations of the two response-latencies. Further, there were always two nil-periods (mean values from end of 6 J. comp. Physiol., Vol. 90 


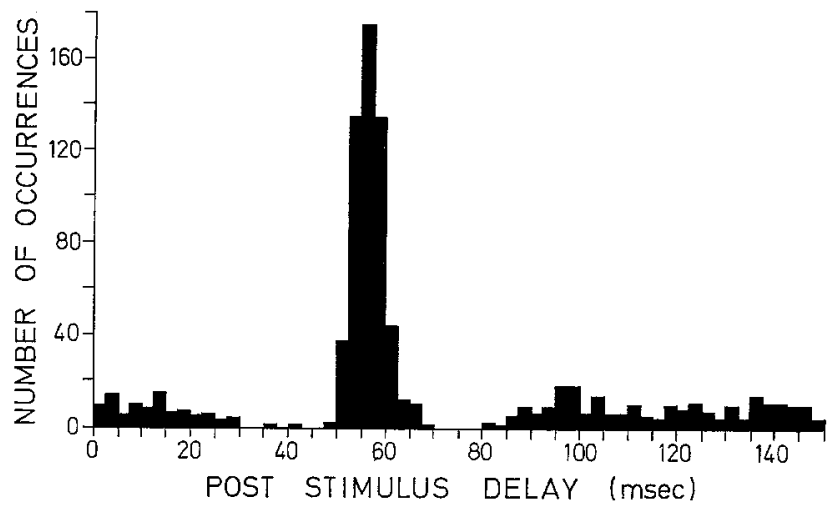

Fig. 5. Post stimulus histogram showing time from beginning of stimulus to beginning of the next call. 927 stimuli were presented to individual No. 6 . Nine stimulus series, varying in stimulus period from 120 to $593 \mathrm{msec}$ were included in this composite histogram. The series selected include both cases where entrainment did and did not occur. Note that in those cases where entrainment occurred, the phase of each stimulus would not be random relative to the previous response. This would result in somewhat more occurrences at 55 and 100 msec than would have been the case if all such phases were random. Calling occurred during all series. Bin width: $2.5 \mathrm{msec}$

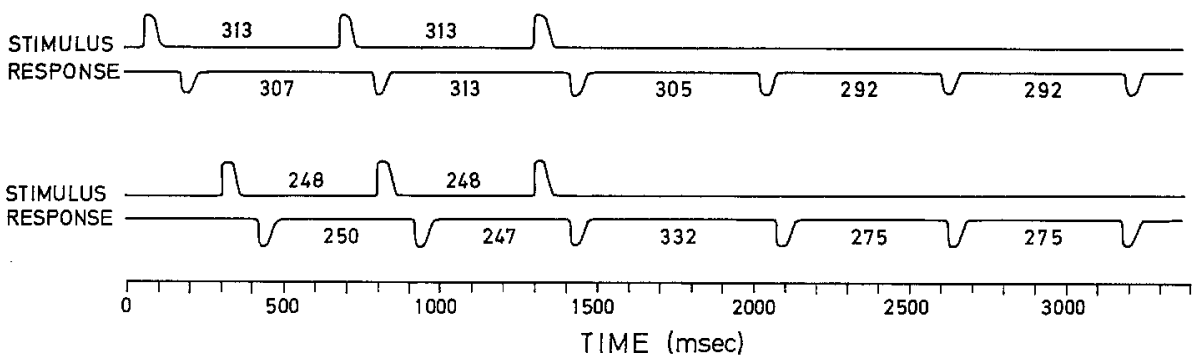

Fig. 6. Tracings from a two channel pen recorder showing individual No. 2 entrained to a group of stimuli and continuing calling after the stimulus was stopped. Note that the call period immediately after the last stimulus was longer than normal free-run periods whether the frog was entrained to a relatively long (upper tracings) or short (lower tracings) stimulus period. All values are in msec

stimulus for all individuals: $5.0-21.8 \mathrm{msec}$ and $36.8-55.8 \mathrm{msec}$ ) during which very few calls occurred. For example, in Fig. 5 the post stimulus time histogram was formed by combining all 927 latencies of nine different series varying in stimulus period from 120 to $593 \mathrm{msec}$. In all series, stimulus duration was 25 msec. 


\section{Variation in Call Period Following Entrainment}

Short trains of stimuli were presented to three individuals (No. 1, No. 2, and No. 4) so that the frogs entrained to the stimuli for a few seconds, then called spontaneously for a few seconds, then resumed. entrainment and so on. In all cases, the period between the first spontaneous call after the last stimulus in a train and the previous call was longer than the normal spontaneous call period. The following periods tended to be shorter and more like normal periods. Examples of this phenomenon are shown in Fig. 6.

\section{Discussion}

The following model is presented as an hypothesis which is most compatible both with the results obtained and with previously described models of pacemaker systems (e.g. Hanson et al., 1971). A central pacemaker initiates each call and has a cycle length equal to the spontaneous call period. The call period may be divided into three phases. After each call, a refractory phase occurs and may last until $80 \mathrm{msec}$ or less before the next call. The remainder of the call period consists of the call activation phase which occurs immediately prior to the next call and the excitatory phase which occurs between the refractory phase and call activation phase (see Fig. 7). During the excitatory phase, an acoustic stimulus will evoke a call which occurs about 30 (or in some cases 75) msec after the end of the stimulus. This results in the occurrence of two nil-periods in post stimulus time histograms (Fig. 5). An acoustic stimulus presented during the refractory phase or call activation phase does not evoke a call.

The call activation phase represents the minimum total time taken for an acoustic stimulus to arrive at the auditory receptor (1-2 msec for the sound to travel from the loudspeaker to the frog), and then impulses to pass along the afferent pathway, and then for efferent motor fibers to produce the call by activating the appropriate musculature. Any stimulus which occurs in the call activation phase will be too late in that cycle to produce an evoked call because a spontaneous call would already have been initiated before the stimulus reached the call initiating center. A value of $5 \mathrm{msec}$ for the call activation phase was determined from post stimulus time histograms and is the time from the end of the stimulus to the beginning of the first nil-period (e.g. Fig. 5). Stimuli falling within this $5 \mathrm{msec}$ period consistently failed to evoke a response. However, it is difficult to envisage the entire neural transmission process described above taking place within $5 \mathrm{msec}$. One possibility is that the beginning of the stimulus effectively halts the production of the next spontaneous call and the end of the stimulus actually evokes (triggers) 


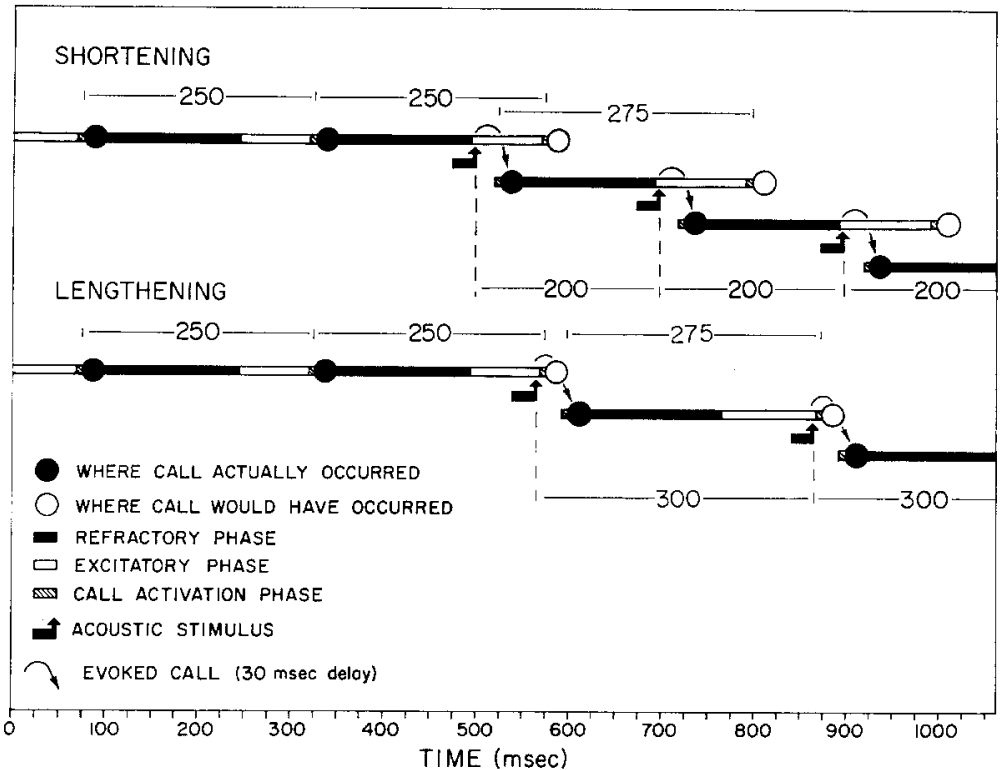

Fig. 7. Diagram showing how, according to the model proposed, a male of $P$. streckeri could maximally shorten or lengthen its call period and entrain to an acoustic stimulus with a period different from its spontaneous call period. An evoked call is triggered by the end of each stimulus. The excitatory phase begins $80 \mathrm{msec}$ before the end of the call period so that, when the stimulus occurs at the beginning of the excitatory phase, the call period will be shortened by $50 \mathrm{msec}$. Note that the excitatory phase lengthens by $25 \mathrm{msec}$ after an evoked call. Thus, the call period is lengthened by $50 \mathrm{msec}$ when the stimulus occurs at the end of the excitatory phase. The call activation phase is shown as $5 \mathrm{msec}$ but may be as long as $30 \mathrm{msec}$ (see Discussion). All values are in msec

a response. The call activation phase may then be as long as $25+5$ $=30$ msec. That there might be a complex interaction between the effects of the beginning and the end of the stimulus is indicated by the fact that the evoked call of one individual (No. 7) was consistently triggered by the beginning of the stimulus regardless of the stimulus duration (Table 2); on the other hand, for four of the other five individuals tested, there was, on 13 out of 15 occasions, a constant delay of 26-37 msec between the end of the stimulus and the beginning of the response, suggesting that in these cases the response was triggered by the end of the stimulus.

After an evoked call, the excitatory phase increases somewhat in length (Fig. 6), so that entrainment will occur for a range of stimulus 
periods considerably longer than the spontaneous call period (Fig. 7). (The possibility that the refractory phase increases in length is not compatible with the shortening process described below.) The maximum increase in the call period ranged from $35 \mathrm{msec}$ (No.4) to $50 \mathrm{msec}$ (No. 5) (see Fig. 3). Stimulus periods somewhat shorter than the spontaneous call periods will be entrained to because a stimulus occuring early in the excitatory phase, say at the beginning of an excitatory period $75 \mathrm{msec}$ long, will result in a call $30 \mathrm{msec}$ later. Hence, this evoked call will occur 50 msec earlier than the next spontaneous call could have occurred (Fig. 7). Shortening of the period by $60 \mathrm{msec}$ represents an upper limit (e.g., Fig. 3, No.5). Apparently, in some individuals the excitatory phase is very short or non-existent and stimulus periods shorter than the spontaneous call periods cannot be entrained to (e.g., Fig. 3, No. 4). Examples of maximum lengthening and shortening of the call period are shown diagrammatically in Fig. 7.

Individual No. 2, when presented with a continuous tone, called at two different rates, one probably corresponding to its spontaneous call rate (call period about $265 \mathrm{msec}$ ) and one a little slower (call period about $295 \mathrm{msec}$ ) (compare data for No. 2 in Figs. 1 and 3). There was no pattern discernable during the calling and it remains unclear as to why the two periods were present.

There is now evidence from behaviorally and neurophysiologically determined auditory thresholds that not all frequencies to which the auditory system of $P$. streckeri is sensitive will evoke calling. Further, in order to evoke a call, acoustic stimuli must be presented at progressively higher intensities as the stimulus frequency is raised or lowered relative to the call frequency (Capranica, Moffat and Loftus-Hills, unpublished data). This situation may be similar to that described for two other species, Limnodynastes dumerili (Loftus-Hills, 1971) and Pseudophryne semimarmorata (Loftus-Hills, 1973) in which it has been postulated that input from the basilar papilla (one of the two auditory organs known in frogs) influences a central pacemaker.

Presumably, a number of complex factors apart from sound influence the activity of the proposed pacemaker. The fact that calling normally occurs only during the night and only during certain months of the year (observations by the writer) indicates that internal (e.g., hormonal) and/or external (e.g., visual) cues are involved. Although not enough is known to warrant speculation about possible anatomical regions that might be associated with pacemaker activity, it should be mentioned that Schmidt (1971) has identified a number of neural centers involved with vocalization, one of which is supposedly influenced by hormonal input. 
The entrainment behavior of $P$. streckeri shows certain similarities to the synchrony and flash entrainment described for certain species of firefly (Hanson et al., 1971). These authors proposed that an oscillator driving normal flashing is reset by an appropriate stimulus. Major differences between the firefly and frog behavior include: (1) in the case of the firefly, a stimulus immediately resets the rhythm whereas in the frog a stimulus triggers a response and resetting occurs in the next cycle; (2) a stimulus resets to the normal free-running rhythm in the firefly; (3) the firefly has no refractory phase. In spite of such differences, the calling behavior of $P$. streckeri can usefully be considered within the general framework of the model of Hanson et al. (1971). For example, difference (2) above can be explained in terms of the firefly model by supposing that in the frog, the oscillator is discharged more completely when triggered by an acoustic stimulus. This may result in a longer spontaneous period immediately after a triggered cycle, regardless of whether that triggered cycle was abnormally short or long (Hansonet al., 1971). Resetting of the call cycle also is known to occur in the frogs Limnodynastes dumerili (Loftus-Hills, 1971) and Leptodactylus albilabris (G. E. Drewry, pers. comm.).

The behavioral analysis made in this paper has led to certain predictions about the acoustic entrainment of one frog by another. The range of call periods to which a frog will entrain includes most of the natural variations of spontaneous call periods (Table 1). Thus, most males should be able to entrain to other conspecific males in a breeding assemblage. As mentioned previously, the adaptive significance of this behavior may lie in a form of time sharing; by entraining to other individuals, a male may signal more effectively by minimizing call overlap and the resulting acoustic interference (Loftus-Hills, 1971). Obviously many questions remain unanswered. For example, what determines which of two frogs will entrain to which? What happens when three frogs are attempting to entrain to each other? What is the significance of the second, longer response-latency? Does leading or following confer any reproductive advantage? This last question is particularly important and there is evidence that in one anuran species, Engystomops pustulosus, that the leader of a group of calling males has the greatest reproductive success (Brattstrom and Yarnell, 1968). All these questions may best be answered by studies of acoustic interactions in natural breeding choruses.

The author acknowledges the support of Dr. W. F. Blair at the University of Texas at Austin and Dr. R. R. Capranica at Cornell University. This work was supported in part by NIH grant NS 09244 to Dr. R. R. Capranica. Mr. R. Sage assisted with recording and collecting in the field. Dr. J. L. Larimer and Mr. J. A. 
Paton provided assistance and advice during initial phases of the analysis. Drs. R. R. Capranica, F. E. Hanson and M. J. Littlejohn criticized the manuscript.

\section{Reierences}

Brattstrom, B. H., Yarnell, R. M.: Aggressive behavior in two species of leptodactylid frogs. Herpetologica 24, 222-228 (1968)

Capranica, R. R.: The evoked vocal response of the bullfrog. Cambridge, Massachusetts: M.I.T. Press 1965

Gerhardt, H. C.: Reproductive interactions between Hyla crucifer and Pseudacris ornata (Anura: Hylidae). Amer. Midl. Natur. 89, 81-88 (1973)

Hanson, F. E., Case, J. F., Buck, E., Buck, J.: Synchrony and flash entrainment in a New Guinea firefly. Science 174, 161-164 (1971)

Heiligenberg, W.: The effect of stimulus chirps on a cricket's ehirping (Acheta domesticus). Z. vergl. Physiol. 65, 70-97 (1969)

Jones, M. D. R.: The acoustic behaviour of the bush cricket Photidoptera griseoaptera. 2. Interaction with artificial sound signals. J. exp. Biol. 45, 31-44 (1966)

Lemon, R. E.: Vocal communication by the frog Eleutherodactylus martinicensis. Canad. J. Zool. 49, 211-217 (1971)

Littlejohn, M. J., Martin, A. A.: Acoustic interaction between two species of leptodactylid frogs. Anim. Behav. 17, 785-791 (1969)

Loftus-Hills, J. J.: Neural correlates of acoustic behavior in the Australian bullfrog Limnodynastes dorsalis (Anura: Leptodactylidae). Z. vergl. Physiol. 74, 140-152 (1971)

Loftus-Hills, J. J.: The neural basis underlying acoustic behavior of the frog Pseudophryne semimarmorata (Anura: Leptodactylidae). Anim. Behav. 21, 781787 (1973)

Loftus-Hills, J. J., Littlejohn, M. J.: Mating-call sound intensities of anuran amphibians. J. Acoust. Soc. Amer. 49, 1327-1329 (1971)

Schmidt, R. S.: Hearing and responses to calls in anurans. Behaviour 23, 280-293 (1964)

Schmidt, R. S.: A model of the central mechanisms of male anuran acoustic behaviour. Behaviour 39, 288-317 (1971)

Shaw, K. : An analysis of the phonoresponse of males of the true katydid, Pterophylla camellifolia (Fabricius) (Orthoptera: Tettigoniidae). Behaviour 31, 203260 (1968)

Walker, T. J.: Acoustic synchrony: two mechanisms in the snowy tree cricket. Science 166, 891-894 (1969)

Dr. Jasper J. Loftus-Hills

Museum of Zoology

The University of Michigan

Ann Arbor, Michigan 48104

USA 